\title{
Immunotherapeutic GSK1572932A
}

National Cancer Institute

\section{Source}

National Cancer Institute. Immunotherapeutic GSK1572932A. NCI Thesaurus. Code C91714.

An immunotherapeutic containing a proprietary adjuvant system combined with a melanoma-associated antigen peptide MAGE-A3 epitope with potential immunomodulating and antineoplastic activities. Intramuscular administration with GSK1572932A may stimulate the immune system to exert both humoral and cellular immune responses against MAGE-A3-expressing tumor cells. MAGE-A3, a tumor associated antigen (TAA), is overexpressed in a variety of tumor cell types, including nonsmall cell lung cancer (NSCLC), melanoma, head and neck cancer, and bladder cancer. 